\title{
A psychological and medical analysis of temperament, character and behavior in children and adolescents of school refusal.
}

\author{
Han Xueqing ${ }^{1 *}$, Zhang Yanbo', Niu Yajuan ${ }^{2}$, Cui Shaojuan ${ }^{1}$ \\ ${ }^{1}$ Beijing Tongren Hospital, PR China \\ ${ }^{2}$ Beijing Hui Long Guan Hospital, PR China
}

\begin{abstract}
Objective: To analyse the teenagers' school refusal behavior and its relationship with their as well as their parents' temperament and character.

Methods: The patients were matched by a ratio of 1:3 in age to gender for clinical studies. Adolescents who refused to go to school and their parents were selected from the mental outpatients of our hospital as the study group (n=55) and those who did not refuse to go to school together with their parents were the control group $(n=165)$. Adolescents in the two groups were asked to fill out questionnaire of general information as well as Teenager Temperament Character Inventory (JTCI-S) and their parents were told to fill Chinese version of Temperament Character Inventory (TCI-R140).

Results: The teenagers in the study group had higher HA score and lower score in NS, RD, SD, CO and PS than those in the control group with statistically significant difference in between $(\mathbf{P}<0.05)$. Fathers in the study group had lower RD than those in the control group. The mothers' RD and ST scores in the study group were lower than those in the control group and the difference was statistically significant $(\mathbf{P}<\mathbf{0 . 0 5})(\mathbf{S R}<\mathbf{0})$.

Conclusion: There are significant differences in self and parent's temperament and character between the adolescent of school refusal and those of school refusal in the control group. For teenagers with unusual family style, factors like high harm avoidance pose certain risks to school refusal behavior. In addition, the teenagers have the characteristics of novelty seeking, reward dependency and cooperative disposition, which provides certain protective factors for school refusal behavior.
\end{abstract}

Keywords: Teenagers' school refusal behavior, Temperament and character, Parent's character.

\section{Introduction}

School Refusal Behavior (SRB) mainly means that teenagers voluntarily refuse to go to school or fail to stay in campus for a whole day [1]. These young people are completely absent from or late for school in a certain period of time, skip some classes or leave the campus in one day [2]. In the morning, when it comes down to attending school, they will act inappropriately, for example they may lose their temper by refusing to leave home, ending in truancy or resignation with extremely pain in class. Under such circumstance they will beg to be excused from school. The school refusal behavior has a detrimental effect on young people's growth. Research shows that $[3,4]$, in China the research on school refusal behavior in teenagers is still in the initial stage and the study of family in this regard relies solely on the way of home education. In this research we mainly studied the relationship between school refusal behavior and teenagers' temperament and character as well as their patients' as follows.

\section{Data and Methods}

\section{General information}

School refusal behavior group (SRB group): The patients were matched by a ratio of $1: 3$ in age to gender for clinical studies. Adolescents who refused to go to school and their parents were selected from the mental outpatients of our hospital as the study group $(n=55)$ and those who did not refuse to go to school together with their parents were the control group $(n=165)$. The adolescents including 115 males and 105 females were aged 12-18 with a mean age of $(13.5 \pm$ $2.5 \mathrm{y})$. The mean age of adolescents in study group was (13.7 \pm $2.1 \mathrm{y})$, and the mean age of adolescents in control group was $(13.4 \pm 2.3 \mathrm{y})$, no significant differences in age was found between two groups.

\section{Methods}

Adolescents in the two groups were asked to fill out questionnaire of general information as well as Teenager 
Temperament Character Inventory (JTCI-S) and their parents Chinese version of Temperament Character Inventory (TCIR140). 1. In JTCI-S there were a total of 108 questions required to be answered by "yes or no", respectively scored "1 or 0" in which temperament contains four dimensions, namely Novelty Seeking (NS), Harm Avoidance (HA) and Reward Dependency $(\mathrm{RD})$ on while character includes three, namely Self-Direction (SD), Collaboration (CO) and SelfTranscendence (ST). 2. In Chinese version of (TCI-R140) there were a total of 140 questions about temperament and character in which the former included the dimensions of NS, HA, RD as well as PS, and the latter SD, CO as well as ST. Each dimension was divided into 5 levels as follows: level 1: complete inconformity, 2: most inconformity, 3: uncertainty, 4: most conformity and 5: complete conformity [5].

\section{Statistical processing}

SPSS17. 0 statistical Software was used for data analysis with t-test for check. $\mathrm{P}<0.05$ suggested there was statistically significant difference.

\section{Comparison of JTCI-S scores between the two groups}

Compared with the control group, the RSB group had higher score of Harm Avoidance (HA) but scores of Novelty Seeking (NS), Reward Dependency (RD), Self-Direction (SD), Collaboration (CO) and Persistence (PS) with statistically significant difference in between $(\mathrm{P}<0.05)$, as shown in Table 1.

Table 1. Comparison of JTCI-S scores between the two groups (score, $\bar{x} \pm s$ ).

\begin{tabular}{|c|c|c|c|c|c|c|c|}
\hline Group & $\mathbf{n}$ & HA & NS & RD & SD & $\mathrm{CO}$ & PS \\
\hline RSB group & 55 & $13.02 \pm 4.525$ & $7.86 \pm 2.56$ & $4.26 \pm 2.25$ & $8.78 \pm 3.56$ & $13.02 \pm 4.25$ & $2.84 \pm 1.56$ \\
\hline Control group & 165 & $9.87 \pm 4.06$ & $8.56 \pm 2.65$ & $5.10 \pm 2.01$ & $10.45 \pm 3.25$ & $16.24 \pm 2.65$ & $3.25 \pm 1.54$ \\
\hline $\mathrm{t}$ & & 7.256 & -3.012 & -3.051 & -3.565 & -5.658 & -2.365 \\
\hline$P$ & & 0.000 & 0.026 & 0.010 & 0.000 & 0.000 & 0.012 \\
\hline
\end{tabular}

Table 2. Comparison of TCI-R140 scores in fathers between the two groups (score, $\bar{x} \pm s$ ).

\begin{tabular}{lll}
\hline Group & $\mathbf{n}$ & RD \\
\hline SRB group & 36 & $66.58 \pm 8.05$ \\
\hline Control group & 78 & $70.56 \pm 21.05$ \\
\hline $\mathrm{t}$ & & -2.549 \\
\hline $\mathrm{P}$ & & 0.013 \\
\hline
\end{tabular}

Table 3. Comparison of TCI-R140 scores in mothers between the two groups (score, $\bar{x} \pm s$ ).

\begin{tabular}{llll}
\hline Group & $\mathbf{n}$ & $\mathbf{R D}$ & $\mathbf{S T}$ \\
\hline SRB group & 45 & $66.75 \pm 6.05$ & $43.25 \pm 8.45$ \\
\hline Control group & 102 & $75.02 \pm 23.54$ & $48.56 \pm 8.56$ \\
\hline $\mathrm{t}$ & & -5.045 & -3.541 \\
\hline $\mathrm{P}$ & & 0.000 & 0.006 \\
\hline
\end{tabular}

\section{Comparison of temperament and character among the parents between the two groups}

The results showed that fathers in the SRB group had lower score of RD and mothers in the SRB group had lower scores in $\mathrm{RD}$ as well as ST than those in the control group with statistically significant difference in between $(\mathrm{P}<0.05)$ as shown in Tables 2 and 3.

\section{Discussion}

Teenagers are going through puberty in the stage of development and at this point they will experience large degree of psychological growth as well as changes with relatively short duration. They are often subjected to such relatively complex contradictions as immature and mature as well as dependence and independence, which makes the students in this period more prone to psychological and behavioral biases [6-9]. A person's personality is an integration of unique and stable mental disposition as well as psychological characteristics [10-12].

The study shows that the adolescents who refuse to go to school exhibit to certain extent such manifestations as pessimism, anxiety, depression, fear of uncertainty, fatigue, apathy and laziness and so on. In addition, some of them show irresponsible, undisciplined and self-centred performance [13]. All these students, compared with those who did not refuse to go to school, have specific personal traits [14]. This study shows that in dimensions of adolescent temperament the harm avoidance is a risk factor for school refusal behavior. The adolescents with anxiety tend to be too scrupulous, nervous, sensitive and unsociable in personality traits meanwhile they have moderately poor social adaptive ability and tense interpersonal relationships, prone to suffer from disorders in emotion and behavior, which will more easily lead to the incidence of school refusal. The novelty seeking, reward dependence and cooperation contribute to factors of school refusal behaviour and proper novelty seeking would drive the behaviour to develop toward inward obstacles, which is a suppression of behavior and to some extent reduces the occurrence of refusal to school [15]. The high score of reward 
refusal

dependency helps an individual quickly respond to the request sent by others, thus generating warm attachment in one another and constructing stable and good social relationship as well as social support system [5].

In summary, because parents are main caregivers of a teenager in his or her daily life and learning process, their personality will exert certain influences on the temperament and school refusal behavior in adolescences.

\section{References}

1. Liu Q, Shenglong Q. A study on the complexity of educational policy in migrant children-taking $\mathrm{C}$ district of Beijing city as an example. J Chinese Soc Edu 2015; 16 : 20-27.

2. Liu Q, Feng Y, Shenglong Q. A study on the cultural mechanism of interaction between family education and school education-based on the field observation of migrant workers educational activities in Beijing. Edu Res 2012; 7: 22-28.

3. Xu N. A study on the relationship between body mass, personality traits and self-identity in adolescents. J N China Coal Med Coll 2012; 14: 629-630.

4. Xing L, Yu L. Personality characteristics of phone dependent adolescents and relationship with sleep quality. Chinese Nurs Res 2016; 30: 1269-1273.

5. Zhou C, Su Q, Wang Y. Study on the heterogeneity of educational investment of rural family children under rural household differentiation-also on the influence of shadow education in the equalization of educational outcomes. Edu Econom 2017; 33: 62-68.

6. Kochanska G, Friesenborg AE, Lange LA. Parents personality and infants temperament as contributors to their emerging relationship. J Personal Soc Psychol 2004; 86: 744-759.

7. Puff J, Renk K. Mothers temperament and personality: their relationship to parenting behaviors, locus of control, and young childrens functioning. Child Psych Human Develop 2016; 47: 1-20.
8. Yilmaz ED, Unal O, Palanci M. The relation between the nine types temperament model and the five factor personality model in a Turkish sample group. Br J Med Res 2016; 21: 227-241.

9. Ardani AR, Naghibzadeh B, Hosseini FF. Temperament and character personality profile and affective temperaments in self-poisoning nonlethal suicide attempters. Psych Res 2015; 229: 394-400.

10. Mackay JRD, Haskell MJ. Consistent individual behavioral variation: the difference between temperament, personality and behavioral syndromes. Anim J MDPI 2015; 5: 455-478.

11. Hong RY, Tan CS, Lee SSM. Interactive effects of parental personality and child temperament with parenting and family cohesion. Parenting 2015; 15: 92-118.

12. Farrell AH, Brook C, Dane AV. relations between adolescent ratings of Rothbarts temperament questionnaire and the HEXACO personality inventory. J Personal Assess 2015; 97: 163-171.

13. Helles A, Wallinius M, Gillberg IC. Asperger syndrome in childhood-personality dimensions in adult life: temperament, character and outcome trajectories. BJ Psych Open 2016; 2: 210-216.

14. Agrati D, Browne D, Jonas W. Maternal anxiety from pregnancy to 2 years postpartum: transactional patterns of maternal early adversity and child temperament. Arc Womens Mental Health 2015; 18: 693-705.

15. Yang X, Jiang L, Li Q. Investigation and intervention study of school refusal in chil-dren and adolescents. J Clin Psychosom Dis 2017; 23: 59-65.

\section{*Correspondence to}

Han Xueqing

Beijing Tongren Hospital

PR China 